Methods A group of transgender sex workers (100) have been interviewed one by one in a closed door from March 2014 December 2014 within Save the Children office. The interview questions asked were issues faced by them when doing sex work in Port Moresby City in Papua New Guinea and how Save the Children SRH Poro Sapot Project has impacted on their lives.

Results

- not receiving good sexual health services from the Governmental clinic's

- Most trans gender sex workers we are raped

- not able to be served at the police stations when in need of help

- being forced to have sex without condom because we are just a sex objects

Conclusion Through advocacy do by Save the Children they have realised who they are, they are aware of their human rights, health and legal issues, they are marginalise group that exist and more mobilised, they have been attending meetings international and national meetings to know the concept of being a Most At Risk Population and through Save the Children SRH Poro Sapot Project they have a voice to represent themselves and other transgender sex works in Papua New Guinea, some trans gender can get help that we need now because Save the Children is referring they to the right networking partners that are providing services that we need like VCCT/and STI checkups and other services that its free from stigma, discrimination and violence.

Disclosure of interest statement Save the Children Sexual and Reproductive Health Program is funded by DFAT or AusAid.

\section{P14.24 MULTICULTURAL SURVEY - ASIAN FEMALE SEX WORKER DEMOGRAPHICS, MIGRATION AND SEXUAL HEALTH IN SYDNEY}

${ }^{1} \mathrm{~L}$ Martin, ${ }^{1} \mathrm{C}$ Thng*, ${ }^{2} \mathrm{H}$ Wand, ${ }^{1,3} \mathrm{~A}$ McNulty, ${ }^{1} \mathrm{R}$ Foster, ${ }^{2} \mathrm{~S}$ McGregor. ${ }^{7}$ Sydney Sexual Health Centre, Sydney, Australia; ${ }^{2}$ The Kirby Institute for Infection and Immunity in Society, Sydney, Australia; ${ }^{3}$ School of Public Health and Community Medicine, University of New South Wales, Sydney, Australia

\subsection{6/sextrans-2015-052270.536}

Theme Social policy, behavioural change, psychosocial or psychosexual issues related to sexual health.

Background Sydney Sexual Health Centre (SSHC) provides dedicated clinics, outreach services and bilingual health education staff to Chinese and Thai sex workers. We aimed to assess characteristics of these sex workers.

Methods A cross-sectional survey was conducted between August 2014-March 2015 using a structured questionnaire in Thai and Chinese, offered to female sex workers attending SSHC and within parlours visited by outreach staff.

Results 338 participants were recruited: 106(32\%) Chinese and 232(68\%) Thai. Overall median age was 31 years. More than half $(56 \%)$ did not attend high school, with Chinese participants less likely to have attended high school than Thai $(67 \%$ vs $50 \%$; $\mathrm{p}=0.003)$. Compared with those attending the clinic, women seen on outreach were older $(42 \%>35$ vs $20 \%$ from clinic; $p$ $=0.00)$ and less likely to have done sex work previously $(90 \%$ vs $71 \%$ from clinic; $\mathrm{p}=0.00)$.

Compared to Thai, Chinese participants were more likely to report "poor" English skills in speaking (61\% vs $27 \%$ Thai), reading (70\% vs $31 \%$ Thai) and writing ( $78 \%$ vs $39 \%$ Thai) $(\mathrm{p}<0.001)$.
While the majority of participants were not on a sex work contract $(92 \%)$, those who were contracted were more likely to be Thai $(10 \%$ vs $3 \%$ Chinese; $\mathrm{p}=0.017)$. Significantly more Thai participants worked in massage $(\mathrm{n}=84,36 \%)$ compared with Chinese $(\mathrm{n}=16,15 \%)(\mathrm{p}<0.001)$

Chinese participants were more likely to check clients for signs of STIs $(\mathrm{n}=75,70 \%$ vs Thai $\mathrm{n}=115,50 \%$; $\mathrm{p}<0.001$ ), less likely to douche $(\mathrm{n}=17,16 \%$ vs Thai $\mathrm{n}=112,48 \%$; $\mathrm{p}<$ 0.001 ), and had fewer misconceptions about STI transmission via unprotected oral sex $(\mathrm{n}=64,60 \%$ vs Thai $\mathrm{n}=179,77 \%$; $\mathrm{p}=0.001$.

Conclusion There were significant differences in the characteristics and behaviours of Thai and Chinese sex workers surveyed. Essential education within culturally appropriate health promotion programs should include douching, checking clients for STIs and using condoms for oral sex.

Disclosure of interest statement No conflict of interest.

\section{P14.25 HIV AND STIS AMONG MALE SEX WORKERS ATTENDING AUSTRALIAN SEXUAL HEALTH CLINICS}

${ }^{1,2} \mathrm{D}$ Callander* ${ }^{1,3} \mathrm{P}_{\text {Read, }}{ }^{4,5} \mathrm{~V}$ Minichiello, ${ }^{6} \mathrm{R}$ Hamilton, ${ }^{7,8} \mathrm{EPF}$ Chow, ${ }^{1} \mathrm{H}$ Ali, ${ }^{9,10} \mathrm{D}$ Lewis, ${ }^{11} \mathrm{M}$ Hellard, ${ }^{1,12} \mathrm{~B}$ Donovan. ${ }^{1} T$ he Kirby Institute, UNSW Australia, Sydney, Australia; ${ }^{2}$ Centre for Social Research in Health, UNSW Australia, Sydney, Australia; ${ }^{3}$ Kirketon Road Centre, Sydney, Australia; ${ }^{4}$ Australian Research Centre in Sex, Health and Culture, La Trobe University, Melbourne, Australia; ${ }^{5}$ University of New England, Armidale, Australia; ${ }^{6}$ Barwon Reproductive and Sexual Health Clinic, Geelong, Australia; ' Melbourne Sexual Health Centre, Alfred Health, Melbourne, Australia; ${ }^{8}$ Central Clinical School, Monash University, Melbourne, Australia; ${ }^{9}$ Western Sydney Sexual Health Centre, Sydney, Australia; ${ }^{10}$ Westmead Clinical School, University of Sydney, Sydney, Australia; ${ }^{11}$ Centre for Population Health, The Burnet Institute, Melbourne, Australia; ${ }^{12}$ Sydney Sexual Health Centre, Sydney Hospital, Sydney, Australia

\subsection{6/sextrans-2015-052270.537}

Introduction The sale of sex by gay, bisexual and other men who have sex with men (GBM) has been identified in many parts of the world as an activity with increased transmission risk for HIV and other STIs. It is, however, unknown if HIV/STI prevalence among male sex workers (MSWs) in Australia is higher than it is among GBM who do not sell sex. This study explores the sexual health of MSWs relative to other GBM attending Australian sexual health clinics (SHCs).

Methods De-identified patient data were extracted from 34 SHC databases in Victoria and New South Wales. A cross-sectional analysis was conducted among MSWs and other GBM at their first visit during 2011-2013. HIV/STI prevalence was calculated as the proportion of diagnosed individuals among those tested. Multivariate logistic regression analyses were used to assess factors associated with HIV and other STIs.

Results A total of 471 MSWs presented at participating SHCs between 2011 and 2013, as well as 24,833 other GBM. At first visit, 44 (9\%) MSWs had known HIV infections while of the 396 men tested there were $10(3 \%)$ new diagnoses. Overall, 50 MSW were diagnosed with a bacterial STI at their first visit: $11 \%$ with chlamydia, $6 \%$ with gonorrhoea, and $2 \%$ with infectious syphilis. Among MSWs, HIV infection was associated with increasing age $(\mathrm{p}=0.002)$ but compared to other GBM, selling sex was not associated with HIV infection $(p=0.9)$ nor STI diagnoses $(\mathrm{p}=0.2)$.

Conclusion Although prevalence of HIV and other STIs appears to be similar among GBM regardless of whether or not they sell sex, over one in ten MSWs were diagnosed with HIV or an STI. The higher prevalence among this population underscores the 